\title{
O PROJETO ESCOLA VIVA: a política de educação neoliberal de Paulo Hartung, no Espirito Santo (2003-2016)
}

\author{
Ueber José de Oliveira* \\ Marcos Marcelo Lirio**
}

RESUMO: O presente artigo tem como propósito analisar a política educacional no contexto da chamada Era Paulo Hartung (2003-2016), partindo da hipótese de que foi a partir dela que se adotou de forma mais sistemática e incisiva, no Espírito Santo, a concepção de gerenciamento do Estado pautada, sobretudo, pela lógica neoliberal, na qual os princípios de qualidade total e eficiência passaram a exercer um poder central sobre os rumos políticos e econômicos do Estado do Espírito Santo em termos de política educacional. Para alcançar os objetivos propostos neste estudo, utilizamos como metodologia a análise documental. $\mathrm{O}$ trabalho conclui que a política educacional do Governo Paulo Hartung, materializado no Programa Escola Viva, representa uma escalada rumo ao processo de privatização do sistema público de ensino do Espírito Santo e resulta de um processo antidemocrático, uma vez que não foi fruto de diálogo com a sociedade, mecanismo que consideramos mais adequado para a implementação de políticas públicas na área da educação.

PALAVRAS-CHAVE: Política; Educação; Programa Escola Viva; Era Paulo Hartung

\section{The living school project: the neoliberal education policy of Paulo Hartung, in Espírito Santo (2003-2016)}

RESUME: The purpose of this article is to analyze educational policy in the context of the so - called Era Paulo Hartung (2003-2016), starting from the hypothesis that it was from this that the conception of management was adopted in a more systematic and incisive way in. Of the state governed mainly by the neoliberal logic, in which the principles of total quality and efficiency came to exert a central power over the political and economic directions of the State of Espírito Santo in terms of educational policy. In order to reach the objectives proposed in this study, we used as documentary analysis methodology. The issue concludes that the educational policy of the Government Paulo Hartung, embodied in the Living School Program, represents an escalation of the process of privatization of the public education system of Espírito Santo and results from an undemocratic process, since it was not the result of a dialogue with society, which we consider to be more adequate for the implementation of public policies in the area of education.

KEYWORDS: Politics; Education; Living School Program; Era Paulo Hartung.

\section{El proyecto escuela viva: la politica de educación neoliberal de Paulo Hartung en Espírito Santo (2003-2016)}

RESUMEN: Este artículo analiza la política educativa en el contexto de la Era Paulo Hartung (2003-2016) planteando la hipótesis de que fue a partir de ella que se adoptó de manera más sistemática e incisiva, en el Estado de Espírito Santo, el concepto de gestión del Estado orientado, sobretodo, por la lógica neoliberal, en la que los principios de calidad total y eficiencia ejercen un poder central sobre los rumbos políticos y económicos del Estado de Espírito Santo en términos de política educativa. Para alcanzar los objetivos propuestos en este estudio, utilizamos como metodología el análisis documental. Llegamos a la conclusión de que la política educativa del gobierno Paulo Hartung, concretizada en el Programa Escuela Viva, representa un escalón rumbo al processo de privatización del sistema público de enseñanza de Espírito Santo y es resultado de un proceso antidemocrático, una vez que no fué fruto del diálogo con la sociedade, instrumento que consideramos más adecuado para la implantación de políticas públicas en el âmbito de la educación.

PALABRAS-CLAVE: Política; Educacion; El Proyeto Escuela Viva; Era Paulo Hartung

\footnotetext{
*Doutor em Ciência Política pela Universidade Federal de Säo Carlos; Atualmente professor do Programa de Pós-Graduação em História Social das Relações Políticas da Universidade Federal do Espírito Santo. Contato: Rodovia BR 101 Norte, KM 60, Bairro Litorâneo, CEP 29932-900, São Mateus-ES, Brasil. Email: ueberoliveira@yahoo.com.br.

**Mestre em Ensino na Educação Básica pela Universidade Federal do Espírito Santo. Atualmente Professor da Rede Municipal de Educação de Cariacica-ES. Contato: Emef Maria Guilhermina de Castro. Rua Santa Leopoldina, Bairro Campo Verde, CEP 29155-820, Cariacica-ES, Brasil. Email: mlmtie@ yahoo.com.br
} 


\section{INTRODUÇÃO}

O presente artigo tem como propósito analisar a política educacional da chamada Era Paulo Hartung (2003-2016). A hipótese é a de que foi a partir desse contexto que se adotou de forma mais sistemática e incisiva, no Estado do Espírito Santo, a concepção de gerenciamento do Estado pautada, sobretudo, pela lógica neoliberal, na qual os princípios de qualidade total e eficiência passaram a exercer um poder central sobre os rumos políticos e econômicos do Estado do Espírito Santo em termos de política educacional.

Os limites do presente trabalho não permitem aprofundar as transformações e impactos trazidos pela adoção do modelo neoliberal na sociedade contemporânea. Para nossos propósitos, basta observar alguns aspectos da hegemonia alcançada pelo neoliberalismo enquanto ideologia que, segundo Anderson (1998, p. 23),

[...] alcançou êxitos num grau com o qual seus fundadores jamais sonharam, disseminando a idéia de que não há alternativas para os seus princípios, que todos, seja confessando ou negando, têm de adaptar-se as suas normas. Provavelmente nenhuma sabedoria convencional conseguiu um predomínio tão abrangente desde o início do século como o neoliberalismo hoje. Este fenômeno chama-se hegemonia, ainda que, naturalmente, milhões de pessoas não acreditem em suas receitas e resistam a seus regimes

Além da lógica neoliberal, o Governo Hartung ocorre em um contexto de forte hegemonia da concepção urbano-industrial, que adquiriu forma no Espírito Santo de maneira tardia e retardatária, a qual busca atender a interesses ancorados na agenda da ONG ES em ação, organismo que congrega diversas empresas de grande porte e que controla a agenda política capixaba, impondo ao conjunto do Estado o seu projeto de desenvolvimento econômico e social.

Pelo fato de se tratar da análise de um período recente de nossa história, a tratamos dentro dos postulados da chamada História do Tempo Presente, campo fundado por François Bédarida em meados da década de 1970 e que trazia como principal inovação a união e a interação entre o presente e o passado, em meio a uma crise de paradigmas das ciências sociais, momento do "retorno vigoroso da história e da memória" (BÉDARIDA, 2005, p. 219). Surgida no bojo das profundas transformações no campo do estudo da história no século XX, essa modalidade ainda não adquiriu total legitimidade entre os historiadores, sendo alvo de muitas críticas, especialmente daqueles que defendem a necessidade do afastamento temporal do objeto como forma de se evitarem as distorções ocasionadas pelas subjetividades. Diante do desafio e das críticas que a produção de uma pesquisa desta natureza pode acarretar, este trabalho busca uma consonância com alguns autores que 
advogam a necessidade de estudar o tempo presente, tais como os Professores Marieta de Moraes Ferreira, Francisco Carlos Teixeira, Janaina Amado, dentre outros, que se tornaram alguns dos principais expoentes da História do Tempo Presente no Brasil.

Assim, o artigo está dividido em três partes, além dessa introdução: na primeira, tratamos da ascensão de Paulo Hartung ao poder nas três ocasiões em que ocupou o cargo de Governador do Estado e seus respectivos contextos. Nesse mesmo item apresentamos as forças políticas que compõem o governo e que, de certa maneira, deram e/ou dão o tom à sua administração em termos de projeto de desenvolvimento.

Em seguida, na segunda parte do artigo, tratamos do projeto Escola Viva e o modo como foi implementado pelo governo, sem qualquer diálogo com a comunidade escolar. Ademais, analisamos também os seus significados e os discursos que foram propalados em torno do referido projeto, seja pela imprensa, por alguns poucos membros do Legislativo Estadual, ou mesmo pelo próprio governo no sentido de defende-lo. Fazemos, outrossim, alguns apontamentos acerca da recepção do projeto por parte dos profissionais da educação bem como dos alunos da rede estadual. $\mathrm{Na}$ análise, verificamos que o projeto, tendo como base o modo como foi executado, está longe de possuir total legitimidade na sociedade capixaba. Por fim, tecemos alguns comentários em termos de considerações finais.

\section{Da chegada de Paulo Hartung ao governo do estado, ao discurso da narrativa de superação do atraso}

A combinação de alguns fatores marcou o cenário da chegada de Paulo Hartung $(\mathrm{PH})^{1}$ ao governo do Estado em 2002, tendo sido reeleito em 2006 e novamente eleito em 2014. O primeiro momento da chamada Era PH ocorreu no contexto de uma forte crise institucional, ética e política vivenciada pelo Espírito Santo no início dos anos 2000 e presente desde a década de 1990, produzida por diversos escândalos de corrupção e até pela significativa penetração do crime organizado nos espaços de poder, envolvendo importantes autoridades políticas e agentes públicos dos mais diversos setores da administração estadual.

O segundo momento de Paulo Hartung como chefe do executivo do Espírito Santo foi marcado pela euforia econômica resultante de novas descobertas minerais que culminaram com a edificação de uma narrativa da esperança quanto ao possível incremento da economia capixaba. E o terceiro momento, ainda em andamento, é a edificação do discurso de PH no que concerne ao cenário da crise econômica nacional que abate o país desde o ano de 2014. 
Devemos salientar que, diante de um cenário turbulento e complexo do primeiro momento, Paulo Hartung ascende como candidato representante de alguns segmentos da elite capixaba, principalmente empresarial, reunida na ONG ES em Ação, a qual passou a apoiar a sua candidatura ao governo, sendo escolhido para reestabelecer um ambiente favorável quanto ao apaziguamento da conturbada crise político-institucional na qual estava mergulhado o Estado. Ao mesmo tempo, a tarefa de PH como legítimo representante desses setores era implementar uma política de infraestrutura adequada para receber os novos investimentos que deveriam ser buscados a partir da edificação dessa nova ambiência institucional. Nesse aspecto, segundo Oliveira Jr.. (2013, p.78):

O governo Hartung foi fruto da necessidade de setores econômicos capixabas e nacionais que visam a adequar as políticas do governo, através da estabilidade política e da formação de uma nova compreensão de gestão do Estado. A priorização técnica na gestão pública foi largamente utilizada nos governos FHC, sobretudo através do planejamento estratégico. A proximidade dos preceitos inicias da tecnocracia estabelecida no primeiro governo Paulo Hartung é tanto pelas políticas quanto pelos executores, o que pode ser observado pelo fato, por exemplo, do secretário de planejamento do período ter sido Guilherme Dias, ex-ministro do governo FHC.

A assimilação dos movimentos nacionais em direção a uma concepção da gestão não pôde se desenvolver no ambiente de crise instalado no estado na década de 90 . O primeiro mandato de PH caracteriza-se no ambiente pela formulação, planejamento e viabilidade do projeto tecnocrático de gestão do Estado no Espírito Santo. Essa máxima pode ser percebida tanto pelo diagnóstico do então novo governador quanto pelo conteúdo dos eixos apontados no documento 'Um Novo Espírito Santo', planejamento de gestão do período 2003-2006.

Dessa forma, PH buscou aplicar, a partir de seu planejamento estratégico, artifícios de orientação tecnocráticos que fossem capazes de metabolizar os novos recursos econômicos, sanando eventuais problemas que emperravam tanto o desenvolvimento das engrenagens da máquina pública quanto dos setores privados do Espírito Santo.

Em seu primeiro mandato, PH também adotou a fórmula da narrativa dos ciclos econômicos como pressuposto explicativo, tanto da crise, quanto do momento de prosperidade que estava por vir, claro, sob seu gerenciamento. Ademais, a “[...] apropriação da narrativa histórica dos ciclos econômicos não foi a única forma de legitimação do 'Novo Espírito Santo' [...]" (NASCIMENTO, 2016, p.196). O uso do passado pelo discurso político também foi recorrente no segundo mandato desse governo.

Em relação ao desenvolvimento da economia capixaba, Hartung (2003) declarou o seguinte, ainda no início do seu primeiro mandato:

[...] O estado do Espírito Santo vem crescendo nos últimos anos a taxas superiores ao crescimento do país. No último ano, eu queria só registrar esse dado, o 
crescimento industrial do Espírito Santo passou de 12\%. Foi o estado com maior crescimento industrial no nosso país. Nos primeiros dois meses deste ano, passou de $20 \%$. Repete o maior crescimento industrial. Quer dizer, na verdade, nós tivemos um desacerto na vida pública, na vida política do estado. Foram três governos, que se sucederam $[\ldots]$

Nesse sentido, era o momento de aproveitar esse crescimento e reorganizar o Estado para o processo de desenvolvimento das atividades econômicas, focando na produção e ampliação da base de lucro, como parte do componente de uma dinâmica mais ampla. Desse modo, o "[...] planejamento estatal visava, nesse momento, reorganizar o Estado para o desenvolvimento das atividades econômicas e para a produção de mais valia, buscando, como parte de um processo internacional, a governança e a regulação das políticas públicas" (OLIVEIRA JR 2013, p.80).

Tendo em vista que o salto da economia brasileira nesse período foi marcado, sobretudo, pelo crescimento das exportações de produtos básicos, tal situação, da mesma forma, contribuiu para dinamizar as expectativas de crescimento também do Estado capixaba. E já que este reunia condições estratégicas para escoar os investimentos, precisava-se, obviamente, investir em uma infraestrutura mais dinâmica, o que, de fato, passou a ser inserido nas ações programáticas da agenda do governo PH e agenda 2025.

Mas não podemos deixar de salientar que o primeiro mandato do governo Paulo Hartung foi beneficiado também pela política do presidente Luiz Inácio Lula da Silva, marcada por acordo para implementação de plantas industriais, investimentos da Petrobrás em pesquisa na região e no adiantamento de recursos provenientes de royalty de petróleo, o que contribuiu para equilibrar as finanças públicas estaduais e acertar os salários do funcionalismo público.

O segundo mandato PH (2007-2010) foi marcado pela reforma gerencial do Estado, a qual reforçou as bases de regulamentação da economia a partir da adoção de políticas públicas reguladoras em sintonia com o processo de desenvolvimento do capital. Nessa perspectiva, no "Discurso de Posse do Governador Paulo Hartung no Palácio Anchieta, em $1^{\circ}$ de janeiro de 2007” (ESPÍRITO SANTO, 2007) PH afirmou:

Precisamos consolidar as mudanças. Em conjunto com a sociedade, não podemos permitir o retrocesso no combate à corrupção e ao crime organizado. Não podemos permitir o retrocesso na austeridade administrativa. Não podemos abrir mão da capacidade de investimentos com recursos próprios. 
Verifica-se, em seu discurso, que Hartung enfatiza a necessidade de não retroceder, o que remete à narrativa do discurso da superação do atraso, tal como descreveu Nascimento, (2016, p. 43), quando destaca-se que:

\begin{abstract}
Ao se apresentar como marco da história do Espírito Santo, de um novo momento, o discurso de posse de Paulo Hartung evidencia a construção da imagem de um 'Novo Espírito Santo', caracterizada pela relação que guarda com a noção de superação característica do discurso político e das representações de Espírito Santo no presente e no passado. Cabe ressaltar que a recorrência a esta ideia por parte de Hartung não foi casual. Pelo contrário, sua força e sentido se encontram em sua relação com a existência de um ideal historicamente elaborado acerca do desenvolvimento local fundamentado na noção de superação do atraso.
\end{abstract}

Uma vez que havia esse novo paradigma administrativo no estado, a educação também passou a ser enquadrada nas engrenagens do modelo de gestão tecnocrático.

Essa racionalização imposta à máquina administrativa passou a enquadrar diversos setores públicos nas agendas da lógica neoliberal, dentre eles a educação, o que passou a afetar a educação pública estadual como um todo.

Destaca-se, nesse segundo mandato, o desmantelamento e a precarização de direitos trabalhistas, regida principalmente por uma nova formatação do trabalho docente dos servidores da educação, que passaram a perceber uma desvalorização gritante, materializada pela perda de direitos e garantias já consagrados. Acerca dessa questão, Oliveira Jr. (2013, p.19) descreve:

\begin{abstract}
Sob a bandeira da qualidade foi instaurada uma nova legislação para regulamentação do sistema estadual de educação; houve a substituição do plano de cargos e salários por uma nova ordem de remuneração do magistério conhecida como subsídio (Lei complementar $\mathrm{n}^{\circ} 428$, de 17 de dezembro de 2007); o estabelecimento do Programa de Avaliação da Educação Básica do Espírito Santo - PAEBES; implementado o novo currículo básico comum (Portaria $\mathrm{n}^{\circ}$ 143-R, de 17 de novembro de 2009) baseado nas noções de competências e habilidades; instaurado o IDE - Índice de Desenvolvimento da Educação (Lei Complementar no 504 de 23 de Novembro de 2009) associado à bonificação por desempenho, além de outras medidas coerentes com as perspectivas das políticas de cunho neoliberal.
\end{abstract}

Desse modo, a trajetória da educação pública estadual do Espírito Santo, no segundo mandato do governo Hartung, foi absorvida por uma agenda política e econômica de cunho neoliberal, orquestrada pela agenda 2025, cujo caráter se encarregou de vincular a educação à concepção gerencial de PH, o que trouxe sérios transtornos, em especial ao magistério. Em relação a esse ataque contra os direitos dos docentes, Rabelo (2010), destaca a fala do Secretário de comunicação do SINDIUPES, Swami Cordeiro Bergamo: 
Esse modelo não respeita professores e alunos e compromete a qualidade do ensino. Este governo trata a educação como mercadoria e professores e alunos como dados estatísticos.

A gestão não é nada democrática. Não existe diálogo. O poder é centralizado na Secretaria de Educação (Sedu). O secretário Haroldo Corrêa Rocha burocratizou o sistema e retirou toda a autonomia das unidades escolares para garantir o total controle em suas mãos.

Assim como o restante da máquina pública estadual, a educação, no segundo governo PH, também sofreu com a orientação dos preceitos da tecnocracia de sua gestão. Esse aprofundamento na burocratização cuidou para que o modelo gerencial de educação fosse enquadrado dentro da lógica tecnocrática do governo Hartung. Desse modo, esse governo deu uma nova roupagem ao seu projeto de educação orientado pela agenda 2025. Nessa perspectiva, Oliveira Jr. (2013, p.85) acrescenta que:

\begin{abstract}
A orientação do processo tecnocrático no Estado do Espírito Santo obedece aos preceitos gerais internacionais, de formatação de parcerias e colegiados multilaterais, esvaziamento dos fóruns do Estado na formulação das políticas públicas, tentativa de 'empoderamento' dos setores sociais junto às escolas como forma do estabelecimento de controle social externo, foco na primeira etapa da educação básica, devido às impossibilidades de inserção produtiva, descentralização, monitoramento e controle dos pretensos resultados, aspectos gerencial acentuado em detrimento do fazer pedagógico.
\end{abstract}

Ao mesmo tempo em que essa regulação foi responsável por forjar a inserção da educação no sistema tecnocrático e gerencialista da segunda gestão do governo Hartung, ela também passou a atuar como um elemento capaz de desarticular a participação popular no que tange a uma construção educacional democrática.

A educação, nesse aspecto, foi sendo absorvida pela lógica gerencial de Hartung e vinculada a organizações formadas por grandes corporações empresariais, como, por exemplo, "Todos Pela Educação". Com esse viés, criou-se o Plano Estratégico Nova Escola: “[...] esse documento busca balizar, de forma específica, a questão da educação [...]" (OLIVEIRA Jr, 2013, p. 88).

Além disso, $\mathrm{PH}$, ao criar mecanismos jurídicos e administrativos como forma de articular as bases de seu projeto de educação, defendido pela elite empresarial capixaba e por segmentos políticos, esvaziou as possibilidades de reação do magistério a esse processo de precarização em que o sistema de educação pública como um todo mergulhou.

Depois de concluir seus dois mandatos (2003-2011), e permanecer por aproximadamente 4 anos afastado de mandato eletivo, PH retornou à disputa pelo cargo de chefe do executivo estadual em 2014, concorrendo com seu então ex-aliado Renato Casagrande. A campanha eleitoral foi protagonizada por sérias acusações mútuas, e 
novamente pela narrativa da superação do atraso (NASCIMENTO, 2016), empunhado por Hartung ao longo de toda a campanha.

Acerca desse momento, pronunciamento revelador ocorreu na convenção do PMDB de 2014, ocorrida em Vitória, na qual foi oficializado o nome de Paulo Hartung como candidato a governador do Estado. No pronunciamento, ficou nítido o ressurgimento da narrativa supramencionada, conforme destacou Souza (2014):

$\mathrm{O}$ atual governo tropeçou nas próprias pernas, afirmou o peemedebista. Com um discurso escrito previamente, o que foge ao costume, Hartung fez questão de afastar a imagem de sua gestão daquela que está sendo feita por Casagrande. 'O governo que se elegeu propondo a continuidade e se comprometendo com o avanço não cumpriu o compromisso com a continuidade, muito menos produziu avanços. Não deu salto algum. Pelo contrário’, frisou Hartung.

Neste aspecto, $\mathrm{PH}$, ao retomar tal narrativa, o fez também como recurso para defender as experiências positivas de seu governo. Segundo ele, foram conquistas como o resultado de uma parceria entre o Estado e a sociedade civil, mas que foram comprometidas pela falta de capacidade de gestão do governo Casagrande. Também de acordo com Souza (2014), Paulo Hartung argumentava que o governo posterior aos seus dois primeiros mandatos "[...] não se fixou numa agenda positiva, jogou suas forças para tentar negar e até mesmo desmontar as conquistas que, em mutirão, o povo capixaba construiu a partir de 2003. Passou a gastar mais, sem entregar obras ou melhores serviços [...]".

Embora Hartung tenha atacado o candidato Casagrande, sempre dizia que não tinha a intenção de "[...] dar pedrada em ninguém. Toda vez que levo pedrada, faço cara de paisagem. Guardo as pedras para construir algo de bom. Quem gasta energia para reclamar tem menos energia para trabalhar [...]" (VICTOR, 2014). O texto destaca ainda que

[...] Em 18 minutos de discurso, o concorrente do PMDB disse que 'o Estado perdeu o rumo, perdeu o ritmo'. Em seguida, relatou: 'Chega de projeto virtual, precisamos de coisas que aconteçam'.

No dia anterior, em evento na quadra da MUG, em Vila Velha, Casagrande insinuara que Hartung retaliava contra os prefeitos que não apoiaram nos dois mandatos que teve, entre 2003 e 2011.

Mas Hartung, perguntado se estava surpreso com o tom crítico do rival nas eleições, foi direto: 'O importante é a campanha que ponho na rua. Capixabas merecem um bom debate sobre o Espírito Santo, com propostas'.

No entanto, no primeiro debate, promovido pela TV Capixaba, Hartung e Casagrande protagonizaram troca de acusações, em alguns momentos eivada de muitas tensões. Sobre tal episódio, Oliveira (2014) destaca que 
Durante todo o programa, Casagrande e Hartung tentaram travar uma disputa particular com a comparação entre os oito anos de governo do peemedebista e os quatro anos do socialista. Ambos com o mesmo discurso do início da eleição. Hartung vendeu novamente a ideia de que seu sucessor não deu sequência ao que ele considera o trabalho de desenvolvimento do Estado, já o governador Renato Casagrande contra-atacou mais uma vez com a afirmação de que o governo recebido não era exatamente a maravilha vendida pelo antecessor.

[...] Casagrande e Hartung trocaram acusações sobre as obras dos Hospitais da Grande Vitória. Hartung criticou Casagrande por atrasar as obras do Hospital Dório Silva e não entregar o São Lucas, acusando o sucessor de ter problemas na gestão.

Nesta perspectiva, o termômetro da campanha eleitoral para governo do Estado em 2014 se acirrou ainda mais entre os candidatos Hartung e Casagrande, principalmente nos horários destinados à Propaganda Eleitoral nas emissoras de rádio e televisão.

Essas acusações entre Hartung e Casagrande permaneceram durante toda a campanha eleitoral e também depois dela, como enfatiza a reportagem do Portal G1 ES "Paulo Hartung, do PMDB, é eleito governador do Espírito Santo" (2014):

Após a vitória, Hartung falou sobre a troca de farpas com o principal concorrente, Renato Casagrande, que disputava a reeleição, durante a campanha eleitoral. Em entrevista coletiva concedida à imprensa, ele falou que se arrepende de ter apoiado a candidatura de Casagrande ao governo do Estado em 2010 e que voltou ao poder para corrigir um erro do passado. 'Estou corrigindo o erro de 2010. O estado perdeu o rumo que tínhamos deixado. Tentaram desconstruir uma obra que foi feita em conjunto com a sociedade. A desorganização não é pequena, vamos colocar novamente o estado no rumo certo', disse.

Diante desse quadro de acusações, depois de eleito, Paulo Hartung fez previsões catastróficas em relação ao cenário administrativo herdado de seu antecessor, Renato Casagrande, tal como descreveu Victor (2014):

\footnotetext{
'As contas se desorganizaram novamente. Mas não sou de chorar o leite derramado. Vamos trabalhar com apoio da sociedade. Vamos dar duro, vamos ter que comer um saco de sal em 2015 para arrumar essa situação', avisou Hartung em entrevista coletiva[...].

Como numa continuação de um enredo que começou durante a campanha eleitoral, Hartung fez mais um discurso de críticas à gestão das finanças do governo Casagrande. Acusou a atual administração de usar o dinheiro das finanças dos royalties e das participações especiais mais para despesas correntes do que para investimentos.
}

Esta narrativa do discurso da superação do atraso, associada à narrativa da "perda de rumo da Gestão Casagrande", proporcionou a Hartung colocar em prática suas ações programáticas de austeridade, inseridas tanto no roteiro de seu discurso, quanto em sua agenda política. Nesse contexto, Paulo Hartung, ao reassumir o posto de chefe do executivo pela terceira vez, em 2015, passou a reeditar essa narrativa da superação do atraso. Em seu discurso de posse isso fica bastante evidenciado: 
Senhoras e senhores deputados, o Espírito Santo dos dias atuais apresenta um cenário desafiante a seu povo. Nos últimos anos, o Estado perdeu rumo e ritmo de crescimento. Assim, precisa retomar o equilíbrio fiscal, a capacidade de investimento com recursos próprios e avançar na direção de uma sociedade verdadeiramente inclusiva e sustentavelmente desenvolvida (HARTUNG, 2015).

A retomada dessa narrativa nos aponta para uma atmosfera que tem como pano de fundo justificar a política de cortes em todos os setores da máquina pública, assim como assumir uma postura política de desmanche das conquistas e avanços no âmbito das políticas públicas educacionais.

Dessa forma, podemos evidenciar que as estratégias utilizadas por Hartung para explicar as dissonâncias econômicas e políticas da gestão anterior fazem parte de um conglomerado de ações táticas, pensadas e executadas como parte de uma proposta maior, e que visou, antes de tudo, a torná-lo um ícone da política nacional.

Ademais, a troca de acusações que marcou a transição de governos, tanto Hartung quanto sua equipe econômica buscaram colocar a prestação de contas de Casagrande em suspeição. Esses frequentes ataques não cessaram durante todo ano de 2015. Hartung, por sua vez, buscou recriar um novo cenário de crise, para que com ele pudesse justificar sua política de austeridade econômica.

Tais afirmações demonstram o quanto PH está comprometido com um determinado projeto de desenvolvimento, proveniente de certos segmentos da elite empresarial, enquanto as políticas sociais, a educação e diversas outras urgências permanecem excluídas de sua agenda, e quando incluídas, estão submetidos aos interesses dos segmentos empresariais a que $\mathrm{PH}$ representa.

Neste tópico, nos empenhamos para reconstruir de forma cronológica a trajetória política de Hartung, desse modo nos possibilitando a compreender o panorama político a ele vinculado, mesmo que tenha sido de forma sintética. Nessa perspectiva, avançaremos no tópico seguinte, aprofundando um pouco mais acerca da política de $\mathrm{PH}$, especificamente a voltada para o seu projeto de educação Escola Viva.

\section{Escola viva: a política educacional de $\mathbf{P H}$}

Retomando o Governo Paulo Hartung e os segmentos de poder que ele materializa, dentre as perspectivas políticas da agenda de Paulo Hartung, desde sua campanha eleitoral de 2014, a educação tem sido um dos pontos mais visados, não porque Hartung se compadeça com ela, mas por sua importância estratégica em seu Plano de Desenvolvimento para ES. 
Nesse contexto, o projeto "Escola Viva", bandeira de sua campanha eleitoral, tornou-se uma de suas principais vitrines políticas. Assim, PH e sua cúpula política vêm impondo esse projeto de maneira antidemocrática a toda a sociedade capixaba.

Por se tratar de um projeto polêmico e cheio de contradições, enfrenta resistências por parte sociedade, da comunidade educacional e de alguns poucos políticos que não se rendem às determinações de Hartung na Assembleia Legislativa, já que o Governador possui amplo controle do Legislativo capixaba.

O projeto Escola Viva, de $\mathrm{PH}$, tem como um de seus gestores a ONG empresarial Espírito Santo em Ação, que é parceira do governo na elaboração do Programa de Governo ES - 2030 e dirigida pela entidade de caráter privado Instituto de Corresponsabilidade pela Educação (ICE), que, entre outras funções, será responsável por coordenar a seleção de gestores e professores, retirando, desse modo, a autonomia do poder público nas decisões que envolvem a educação.

Tal projeto se insere no debate acerca da questão da qualidade da educação básica no Brasil, que, segundo Oliveira (2014, p. 226),

[...] põe no centro das políticas educacionais a avaliação e esta, por sua vez, retira o foco do debate sobre o direito e orienta seus sentidos na racionalidade administrativa que persegue a eficiência a qualquer preço. Em meio à busca de resultados, vai se perdendo no processo a construção histórica da educação como um bem público, um direito social e que, como tal, não pode ser regulada como mercadoria, produto ou resultado passível de mensuração.

E é desta maneira que vem procedendo o Governo $\mathrm{PH}$ : de forma antidemocrática sem discutir o projeto com o conjunto da sociedade -, Hartung o impôs no meio do ano letivo de 2015, surpreendendo de forma negativa a todos da comunidade escolar. Nesse sentido, o polêmico projeto Escola Viva começou a ganhar status de política pública na quarta-feira do dia 4 de março de 2015, data que ficou marcada pela entrega, na Assembleia Legislativa do Espírito Santo, do projeto de Lei que dispunha sobre o Escola Viva, e que deveria ser votado, a pedido de Hartung, em caráter de urgência. Desde a sua implantação, já foram criadas 15 unidades

${ }^{2}$ de Escola Viva, quantidade que, segundo o Governo, deve aumentar nos próximos anos sem, no entanto, fazer qualquer prognóstico mais preciso.

Devemos lembrar que na ALES “[...] 96,9\% das proposições do executivo tramitam em regime de urgência [...]" (PESSINE, 2013, p. 99), ou seja, fato que também explica, em 
parte, a tese de que o seu projeto educacional seria aprovado sem maiores problemas na Casa Legislativa, sem participação da população nas discussões, e sem maiores questionamentos por parte dos deputados, que, por sua vez, compõem quase majoritariamente a base de aliados de Hartung, estratégia que foi dada como certa na lógica do governo.

Porém, por seu projeto estar circunscrito num cenário que excluiu a possibilidade de diálogo com a comunidade escolar e com a sociedade civil organizada, Hartung precisou recuar, tamanha foi a pressão feita por diversos atores sociais, no ano de 2015, que, descontentes com a postura autoritária do governo, reagiram de forma veemente contra o modo como o projeto Escola Viva estava sendo apresentado pelo governo.

Este modelo de educação, amplamente difundido por Hartung em campanha eleitoral, respaldado por segmentos da elite empresarial capixaba, reforça os laços de afinidade e demonstra o modo como o Escola Viva comunga com a agenda política desenvolvimentista desses segmentos econômicos, ao passo que vem sendo narrado, no discurso e na agenda de Hartung, como sendo a solução dos problemas da educação no Espírito Santo.

Para manter o projeto Escola Viva na linha de frente de sua autopromoção política, Hartung tem investido pesado, e também contado com apoio irrestrito da Imprensa local, que, por sua vez, não perde a oportunidade de enaltecer tal projeto, como podemos observar no fragmento de texto a seguir:

\begin{abstract}
Citado em quase todos os programas eleitorais do governo Paulo Hartung no ano passado, a Escola Viva - aquela 'que faz brilhar os olhos do aluno' - enfim, vai sair do plano das ideias. O projeto de lei com as diretrizes da reformulação do ensino médio já está nas mãos da Assembleia Legislativa e deve ser votado em regime de urgência. Na prática, significa o primeiro passo concreto deste governo, em uma ação que nada tem a ver com a herança recebida pela gestão de Renato Casagrande. A concepção dessa nova Escola tem ocupado quase todo tempo do secretário de Educação, Haroldo Corrêa Rocha. Reuniões com consultores e pedagogos têm acontecido diuturnamente e sem previsão de término. Não é por menos: o aliado de longa dada de PH tem nas mãos o projeto que é considerado a 'menina dos olhos do governador' (FACHETTI, 2015).
\end{abstract}

Percebe-se que a matéria enaltece os esforços do governo em desenvolver esse projeto, ao mesmo tempo em que busca dar um verniz democrático em sua construção. Mas, o pano de fundo dessa realidade tem nos mostrado o inverso. Trata-se de uma imposição política, cujo caráter visa não apenas a desestruturar o sistema educacional público, mas também a entregálo à inciativa privada, tal como tem ocorrido no sistema público de educação de Pernambuco, estado pioneiro na adoção do Escola Viva. 
Nessa perspectiva, e relativizando a opinião de Fachetti, Oliveira expôs uma visão bem mais pessimista em relação ao Escola Viva, quando cita a entrevista do dirigente do Sindicato dos Trabalhadores em Educação de Pernambuco Heleno Araújo Filho, que também é secretário de Assuntos Educacionais da Confederação Nacional dos Trabalhadores em Educação (CNTE) e coordenador do Fórum Nacional de Educação. Quando perguntado se houve mudanças substanciais na qualidade de ensino, se ele acreditava que o Escola Viva era um projeto eleitoreiro, e como avaliava a atuação do Instituto de Corresponsabilidade Educacional (ICE) como gestor político, ele destacou que:

\footnotetext{
-Na rede estadual não. Os alunos dentro do programa melhoraram um pouco (a média do IDEB nas escolas do programa é de 4,1), ou seja, média de aprovação abaixo de seis.

- Sim. O ex-governador Eduardo Campos utilizou este pedaço de política (para poucos) para dar sua reeleição no Estado e para projeção nacional, com objetivo de disputar e alcançar a Presidência da República.

- Muito complicado, o programa permite que o ICE coordene a seleção de gestores (não seriam mais funcionários da rede, mas comissionados indicados pelo Instituto) e professores, além de indicar onde seriam instalados os novos centros, tirando do poder público os poderes de decisão e entregando ao setor privado, que utiliza a Tecnologia Empresarial Aplicada à Educação: gestão e resultados, ou seja, fazer da escola uma empresa com interesse voltado para o mercado de trabalho local, um tipo de foco que prejudica alcançar os objetivos estabelecidos na Lei de Diretrizes e Bases da Educação Nacional - LDB Lei n. 9.394/94 (OLIVEIRA, 2015l).
}

Em relação à última resposta, percebemos que tal realidade não é mera coincidência, principalmente no que tange à realidade capixaba e aos objetivos de Hartung com o Escola Viva, uma vez que esse governo tem nesse projeto a oportunidade de retirar do Estado a responsabilidade sobre a educação pública, a entregando à iniciativa privada, uma vez que a sua implantação se desenvolve a partir de terceirização de diversas atribuições da escola.

Quando o projeto Escola Viva foi enviado para votação em caráter de urgência na Assembleia Legislativa do ES (ALES), ocorreram protestos de deputados e professores que consideravam vago o projeto. Nesse sentido, as "críticas também vieram das galerias do Legislativo. Professores e alunos da rede pública acompanharam a sessão plenária e protestaram quando a [sic] urgência do projeto de lei complementar [...]” (VALFRÉ, 2015). Diante do resultado dessa insatisfação conjunta, Hartung retirou, no dia 19 de março de 2015, o pedido de urgência em votação do Escola Viva.

A manobra política de $\mathrm{PH}$, utilizada na ALES, só não contou com a reação da sociedade que, atenta, se manifestou de forma democrática contra um projeto sobre o qual não se abriu nenhum tipo de diálogo no contexto de sua construção. Em relação à imposição desse projeto à comunidade escolar, Gouvêa (2015) relatou que 
Os professores reclamam da falta de diálogo com o sindicato da categoria. A professora de sociologia no Colégio Aristóbulo Barbosa, Fabíola Cerqueira, diz que o projeto é vago e que fere os direitos trabalhistas da categoria. Assim como os alunos, eles teriam que optar por participar do projeto ou não. Em caso de efetivos, em que muitos ocupam cadeira em mais de uma escola, se escolherem participar do projeto, terão que abrir mão de uma cadeira, o que terá consequências na aposentadoria.

A ausência de diálogo não só comprometeu o desenvolvimento da educação pública capixaba, mas também colocou em risco os direitos e garantias do magistério, uma vez que os interesses privados que estão postos nessa questão não se comunicam com os da comunidade escolar, como denunciou o mesmo Gouvêa (2015):

Outras situações apontadas como problemáticas pelos professores são o gerenciamento do projeto, que será feito pelo Instituto de Corresponsabilidade pela Educação (ICE) e os processos seletivos e avaliação pelos quais passarão os professores periodicamente.

"É um processo de terceirização da gestão escolar. Será que nossos profissionais da escola não estão preparados para gerir a escola como um todo? Além disso, não está claro, no projeto de lei, a que tipo de avaliações os professores serão submetidos. Os efetivos que abrirem mão da outra cadeira para participar do Escola Viva terão que passar por outro processo seletivo e não se diz qual é o modelo de seleção", salienta a professora Eliete.

A matemática de Hartung é bem simples: fechar escolas e reduzir gastos, extinguir turnos, diminuindo assim o número de professores e funcionários em geral para que o governo possa dar a sua escola unitária e seletiva um verniz de qualidade e eficiência. Tratase, nesse sentido, de maximizar a participação da iniciativa privada na educação, retirando do Estado a responsabilidade com a educação pública.

Contra essa política de uma escola seletiva e excludente, o Sindicato dos Trabalhadores em Educação Pública do Espírito Santo - SINDIUPES promoveu uma campanha em 2015, por Escola Integral democrática, plural e inclusiva, cujo tema foi 'Escola Viva sem diálogo e participação já nasce morta'. Sobre o evento, Trento (2015) destaca que:

No último dia 23/04/2015, o Sindiupes entregou uma carta aberta aos deputados estaduais, expondo os motivos pelos quais são contrários à criação da Escola Viva, nos moldes que está sendo proposto pelo Governo do Estado [sic]. Na mesma carta pedem aos deputados para que rejeitem o projeto, tendo em vista que o consideram antidemocrático e excludente, impondo mudanças na vida dos profissionais da educação, estudantes, pais e responsáveis. Também prometem divulgar os nomes dos parlamentares e seu posicionamento com relação do projeto.

O deputado Sérgio Majeski, também contrário ao projeto Escola Viva do Estado, disse que o projeto não tem respaldo, pois está baseado numa experiência estadunidense que se revelou um grande fracasso. Ele criticou a justificativa do projeto encaminhado à Assembleia, que não expõe de maneira ampla como o governo pretende fazer essas mudanças e já pediu ao secretário de Educação o projeto inteiro, com a fundamentação teórica, justificativa, objetivos, metas e resultados que todo projeto com essa magnitude tem de ter [...]. 
Nesse contexto, foram muitas as manobras de Hartung para aprovar o seu projeto. Todavia a sociedade civil organizada, movimentos sociais da cidade e do campo, bem como setores da comunidade escolar não deram, nesse período, trégua para Hartung, uma vez que o governo planejava implementar o projeto já no segundo semestre de 2015 , no meio do ano letivo, um exemplo de desrespeito com a comunidade escolar que não teve a oportunidade de opinar, e que já percebia uma atmosfera de caos que seria a sua implementação na metade do ano letivo.

Entre os deputados que questionaram o projeto de PH, Sérgio Majeski se destacou como sendo um dos críticos mais ferrenhos. Por causa desse destaque, a emissora Rede Gazeta de Televisão, preocupada em não expor o Secretário de Educação Haroldo Corrêa Rocha a um debate com o deputado, acerca do projeto Escola Viva, os entrevistou em dias diferentes no programa Bom Dia ES, uma demonstração de que a mídia corporativa buscou blindar o governo de possíveis questionamentos, impedindo que, dessa forma, a sociedade descobrisse as reais motivações desse projeto, que tanto tem sido questionado. Apesar disso, Majeski (2015) nessa entrevista, aproveitou a oportunidade de questionar sobre o modo como o Plano Estadual de Educação estava sendo imposto a sociedade:

[...] o Plano Estadual está tão mal feito que a menina dos olhos do governo do Estado, que é o Escola Viva, ela não está mencionada, nem a Meta que fala sobre o turno integral, não se menciona nesse projeto, e nem a Meta 3 específica do Ensino Médio. Então assim, como esse Plano foi feito? Se nem aquilo que o governo julga como a Revolução do ensino está mencionado no projeto [...].

A fala do Deputado desvela a grande incoerência da política educacional de $\mathrm{PH}$, aponta para a falta de diálogo quando à elaboração e implementação da mesma e, acima de tudo, indica o desrespeito do governo com a sociedade, uma vez que $\mathrm{PH}$ dita as regras, mesmo sendo elas incoerentes em seus propósitos. Apesar disso, PH sinalizou publicamente, e reiteradas vezes, que esse projeto foi amplamente discutido e deliberado com a sociedade. Sabemos que essa declaração é controversa, e o modo como foi votado o projeto no Legislativo Estadual, votação ocorrida no dia 10 de junho de 2015, demonstra isso muito claramente, conforme asseveram os escritos de Oliveira (2015a):

A votação aconteceu na manhã desta quarta (10) graças a uma manobra realizada nessa terça-feira na Assembleia. Uma votação conjunta das comissões de Educação, Assistência Social e Finanças acelerou a aprovação do projeto e aumentou a pressão sobre os deputados para que a proposta fosse votada nesta quarta. Depois da sessão ordinária, o projeto retornou à Comissão de Justiça para 
que fosse feita a redação final da matéria que seria apresentada na sessão de hoje (10).

Depois da votação, o deputado Sérgio Majeski fez um pronunciamento em forma de desabafo. O deputado classificou de "ridícula" a ideia de que o projeto seria a solução para os problemas da educação no Estado. Ele afirmou que a comunidade tem outras demandas e que o governo do Estado não ouviu a comunidade escolar, que tem competência para discutir o assunto.

Mantendo essa postura de exclusão da participação popular das decisões, sete dias após da aprovação do Escola Viva, Hartung novamente ignorou a opinião pública e utilizou de manobra política para aprovar o Plano Estadual de Educação - PEE, um importante documento que foi aprovado sem maiores discussões com a sociedade, como podemos verificar na opinião de Bessa (2015):

Em meio a muita confusão e bate-boca, 25 parlamentares votaram a favor do Plano Estadual de Educação (PEE). O Projeto de Lei 234/2015 - que institui a implantação do plano -, passou pelo Plenário da Assembleia Legislativa (Ales), na manhã desta quarta-feira (17), sem que houvesse debate com a sociedade. O único voto contra foi do deputado Sérgio Majeski (PSDB), que teve todas as 37 emendas sugeridas rejeitadas.

O projeto foi protocolado no início deste mês e tramitou em regime de urgência na Assembleia, já que, de acordo com a recomendação do Governo Federal, todos os estados precisam ter o plano aprovado e sancionado até o próximo dia 24 de junho.

No dia 15 de junho de 2015, foi publicada no Diário oficial do Estado a Lei Complementar $\mathrm{n}^{\circ} 799$, que criou oficialmente o Programa de Escolas Estaduais de Ensino Médio em turno único, denominado "Escola Viva".

Figura 01 - Diário Oficial 


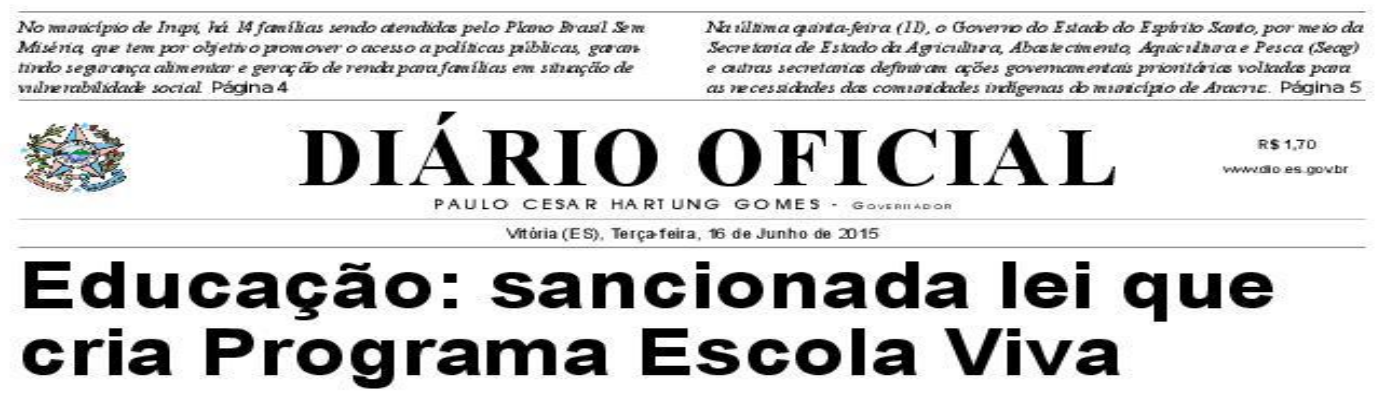

A Lei Complementar No 799, que cria o Programa Escola Viva, foi publicada na edição de ontem (15), do Diário Oficial do Estado

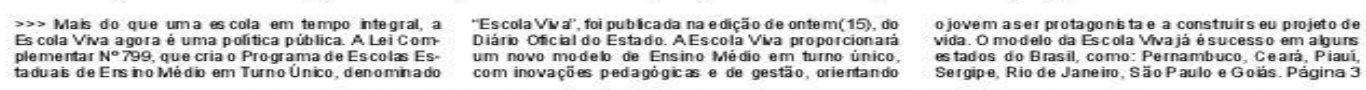

Servidores são capacitados para inovar na gestão pública

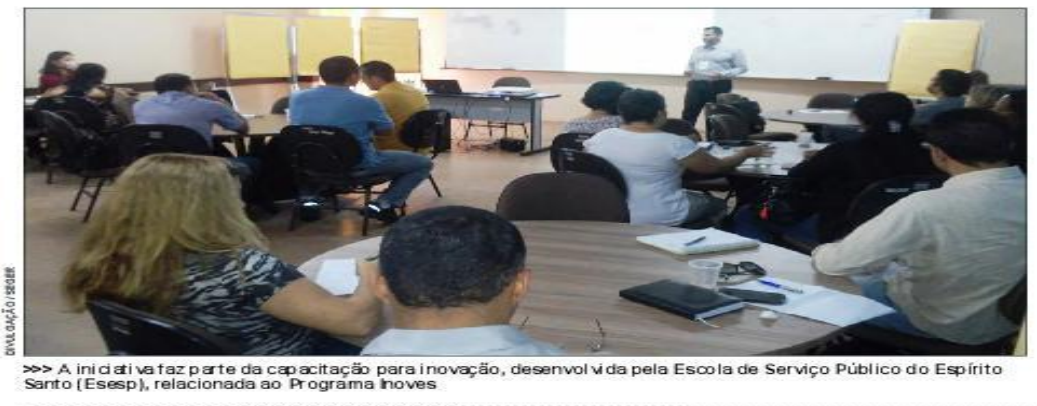

Para se inscrever, basta ficar atento. O site www. esesp.es. gov.br traz a lista completa de cursos

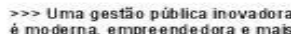
em preparada para oferecer à com foco em resultados. Por iss senidores públicos es taduais e importancia de inovar por meio do cuss o "Inovaçä́o na Gestắo", ofereció Es pirito Santo (Esesp). Ainiciativa to parte da capacictaçäo para inovaçäo, desenvolida pela Esesp, relaciona se guintes cursos: "Inovaçä́o na Gestä́o Púbićca", "Inovar para ompartilham ento ${ }^{\circ}$. Página 6

\begin{tabular}{|c|c|c|}
\hline $\begin{array}{l}\text { Prevenção de } \\
\text { quedas e violência } \\
\text { contra o idoso é } \\
\text { tem a de capacitação }\end{array}$ & $\begin{array}{l}\text { Dicas da Ceasa/ES: } \\
\text { abóbora reduz o } \\
\text { risco de doenças } \\
\text { cardiovasculares }\end{array}$ & $\begin{array}{l}\text { Cultura: grupo } \\
\text { capixaba em } \\
\text { temporada teatral } \\
\text { no Rio de Janeiro }\end{array}$ \\
\hline
\end{tabular}

\section{Cariacica ganha}

im portante

ferram enta de Páging 4

pesquisa

A partir de então, foram muitas as denúncias feitas pela sociedade civil organizada (estudantes, sindicatos e movimentos sociais organizados do campo e da cidade) ao Ministério Público e à imprensa capixaba, acerca dos problemas causados pela implementação desse projeto no Espírito Santo. Um dos problemas considerados mais graves tem sido o fechamento de unidades de ensino e extinção de turnos, tal como destaca Oliveira (2015i):

Hartung se elegeu com a bandeira da educação. O projeto Escola Viva prometia ser uma solução para melhorar a qualidade no ensino. Mas a estratégia da Secretaria de Estado da Educação (SEDU), desde o início do ano, priorizou os cortes de gastos. Para enxugar a máquina, o governo precisa reduzir as verbas para as escolas. Isso seria possível reduzindo o número de turmas; demitindo professores e até mesmo fechando escolas e transferindo os alunos para outras unidades.

Isso expressa o teor do comprometimento de $\mathrm{PH}$ com o desmantelamento do sistema educacional do Estado. Sob o pretexto de modernizar a educação, Hartung passou a enquadrála dentro de seu pacote de ajuste da máquina pública, buscando, dessa forma, passar a imagem de que o governo quer uma educação de qualidade, sendo que, com base no observado desde o início do seu atual mandato, esse governo buscou apenas desenvolver um modelo 
homogêneo de educação no qual possa se minimizar ao máximo os custos, além de retirar do Estado a responsabilidade pela educação.

Enfatizamos que, apesar da defesa do governo, a resistência por parte dos estudantes em relação ao projeto Escola Viva foi rotineira em alguns municípios do Estado, em especial no ano de 2015. No norte do Estado, por exemplo, os estudantes chegaram a ocupar a Superintendência de Educação de São Mateus, objetivando pressionar o governo do estado, como destaca Oliveira (2015c):

Estudantes de três escolas estaduais de São Mateus, norte do Estado, ocuparam a Superintendência de Educação no município [...]. Eles pretendem passar a noite no local e só vão desocupar o prédio depois que o responsável pela Superintendência conversar com o grupo.

Porém, Paulo Hartung tem se mostrado insensível com essas manifestações, utilizando-se até mesmo do aparato policial como forma de coibir a pressão feita pelos estudantes e pela população. Dessa forma, percebemos que o diálogo tem sido o último recurso utilizado pela gestão PH, como ficou constatado em São Mateus:

[...] Pela manhã, durante o protesto, um dirigente da União Municipal dos Estudantes Secundaristas (UMES) de São Mateus foi detido após convocar plenária com estudantes.

Os estudantes seguiram então para a porta do DPJ e fizeram um protesto que culminou com a liberação do militante. A entidade publicou uma nota em sua página no Facebook repudiando a ação. 'A PM agiu de forma hostil e truculenta, desrespeitando os princípios democráticos que determinam a constituição e agredindo o militante. É importante frisar que essa vem se tornando uma prática comum no Espírito Santo, o que deixa evidente que o governo do Estado é despreparado para o diálogo e governa com um viés autoritário e sem participação da sociedade. A UESES e UMES repudiam tal ato e reiteram que tomarão as medidas necessárias para resguardar os seus dirigentes e militantes das atrocidades promovidas pelo governo Hartung', diz a nota (Oliveira2015c).

Figura 02 - Flagrante de intolerância contra estudantes

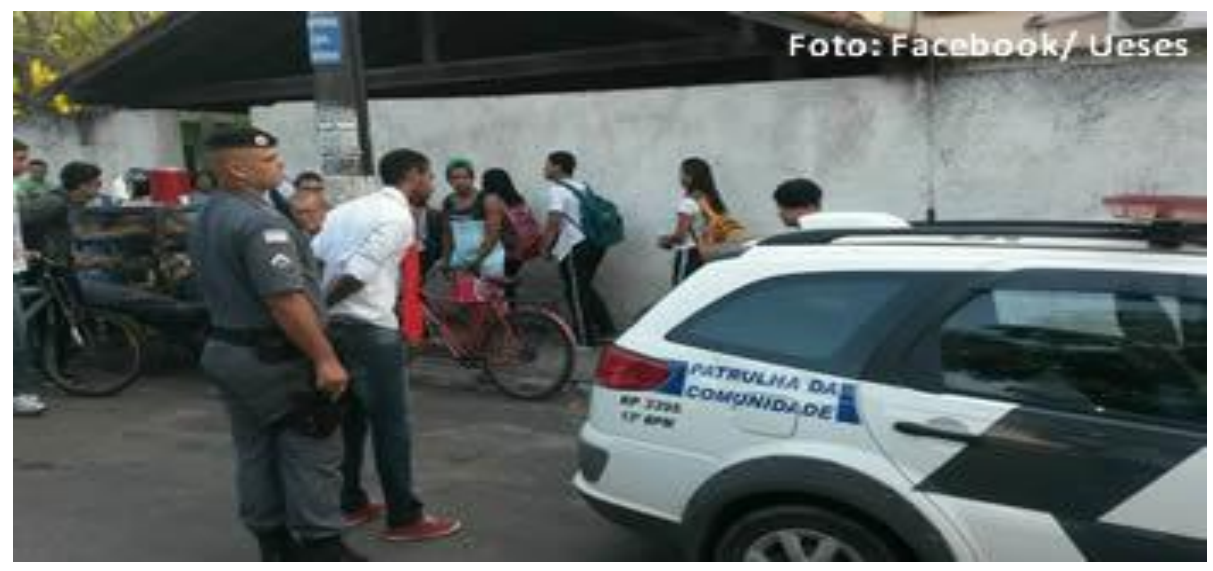


Tal fato se tornou, em 2015, uma realidade dentro do ciclo de protestos e ações contra esse projeto. Em Colatina o governo tentou implantar o projeto na escola Conde de Linhares, mas ocorreu resistência dos alunos e da justiça, que proibiu o Escola Viva no colégio, como descrito abaixo:

\begin{abstract}
O Escola Viva Conde de Linhares, em Colatina (noroeste do Estado), não poderá ser implementado em 2016. A vara da Infância e Juventude de Colatina deferiu a ação civil pública (ACP) ajuizada pelo Ministério Público do Estado (MPES), por meio da Promotoria do município e pela Defensoria Pública do Estado. A decisão determina que o governo do Estado se abstenha de implementar, no ano letivo de 2016, o 'Programa Escola Viva' na unidade.

A comunidade escolar procurou também o MPES e a Defensoria pública para denunciar a falta de diálogo com a comunidade, que rejeitou o programa, preferindo a manutenção dos cursos profissionalizantes, que seriam suspensos com a adoção do ensino em tempo integral.

Na ação, o MPES e a Defensoria sustentam que em reunião com a população e votação do Conselho de Escola, foi decidido de forma unânime pela não adesão ao Programa Escola Viva diante da perspectiva de encerramento dos cursos técnicos oferecidos pela unidade e de transferência de grande parte dos alunos para outras escolas. Essa era a grande preocupação da comunidade escolar, já que as demais escolas da região têm condições de atender o excedente de alunos (OLIVEIRA, 2015h).
\end{abstract}

Percebemos que a gestão Hartung tem se utilizado de instrumentos cada vez mais eficazes como forma de preparar estratégias para que seu projeto de educação antidemocrático seja implementado, como se percebe no texto abaixo:

[...] A escola de Hartung não tem nada de democrática. Ela visa ao enxugamento do aparelho para entregar às Organizações Sociais $(\mathrm{OS})$, um movimento que não é exclusivo do Espírito Santo, vem acontecendo também em outros estados. A diferença é que em outros estados, a comunidade escolar está reagindo, ocupando as escolas, denunciando os abusos do governo.

Enquanto vende seu projeto de vitrine, alinhavado com o velho parceiro ES em Ação, o governo do Estado não melhora em nada a educação do Espírito Santo, que deveria ser direito de todos, mas aos poucos tem se tornado privilégio de alguns [...] (OLIVEIRA, 2015b).

Essa arbitrariedade do governo $\mathrm{PH}$ tem produzido problemas graves em muitas comunidades, fechamento de escolas públicas, fim do horário noturno em algumas escolas, deixando dessa forma sem acesso à educação centenas de trabalhadoras e trabalhadores, redução de carga horária de professores, retirada de direitos.

\title{
CONSIDERAÇÕES FINAIS
}


A presente pesquisa nos leva a duas constatações centrais: o primeiro é que o projeto Escola Viva faz parte de um conjunto de políticas que tem por finalidade passar adiante a responsabilidade da educação pública para a iniciativa privada. O segundo é que tal projeto evidencia uma face autoritária da gestão Hartung que nega abrir canais de diálogo com a sociedade civil organizada na construção desse e de outros projetos que envolvam a educação.

Ao dizer que a "escola é chata" o Secretário de Educação Haroldo Corrêa Rocha não só colocou em xeque todo o sistema educacional público estadual do Espírito Santo, como também desprestigiou a escola pública, uma vez que seu infeliz comentário demonstrou oficialmente a inoperância do governo em relação a educação pública estadual.

Assim, o governo deixa claro que o sistema educacional que ele mesmo gere, formado por centenas de professores e alunos, tem sido um grande fracasso. Apesar da contradição, a ideia é reforçar a tese de que a Escola Viva é, de fato, um receituário, no caso o único, para livrar a educação pública de seu próprio fracasso. Desse modo, é preciso compreender que "enquanto vende seu projeto de vitrine, alinhavado com o velho parceiro ES em Ação, o governo do Estado não melhora em nada a educação do Espírito Santo, que deveria ser direito de todos, mas aos poucos tem se tornado privilégio de alguns" (OLIVEIRA, 2015b).

Cabe ressaltar mais uma vez: sabemos que a dinamicidade desse projeto em curso nada tem a ver com a educação em si, mas se trata de questões econômicas e deslocamento de responsabilidade por parte do Estado, política pensada a partir de uma lógica neoliberal.

\section{Notas}

\footnotetext{
${ }^{1}$ Paulo César Hartung Gomes nasceu em Guaçuí, interior do Espírito Santo, em 21 de abril de 1957. Formado em economia pela Universidade Federal do Espírito Santo (UFES), militou no movimento estudantil entre 1976 e 1981, tendo sido presidente do Diretório Central dos Estudantes (DCE) da UFES após sua abertura, em 1978, depois de dez anos de fechamento pelo regime militar. Dirigente do Partido Comunista Brasileiro (PCB), o Partidão, atuou, em 1979, na reorganização da União Nacional dos Estudantes (UNE), não conseguindo, porém, fazer seu sucessor no DCE, opondo-se aos grupos de tendência vinculados à formação do Partido dos Trabalhadores (PT). Em 1982, Hartung filia-se ao Partido Democrático Brasileiro (PMDB) e lança sua candidatura a deputado estadual. Elege-se a deputado estadual com 25 anos de idade, iniciando sua trajetória parlamentar na Assembleia Legislativa (1983 a 1986). Reelege-se, em 1986, a deputado estadual (1987 a 1990) e, no exercício desse mandato, participa da elaboração da Constituição Estadual, promulgada em 1989, quando se destaca na defesa do meio ambiente. Já filiado ao Partido da Social Democracia Brasileira (PSDB), elege-se, em 1990, a deputado federal (1991 a 1994), obtendo a maior votação do Município de Vitória. Nesse cargo, como deputado federal, ocupa a vice-liderança do PSDB na Câmara dos Deputados, tendo sido também membro da Comissão Mista de Orçamento. Concorre, em 1992, à Prefeitura de Vitória-ES, ocupando o cargo de Prefeito entre os anos de 1993 e 1996. Participa, em 1997, nos Estados Unidos, a convite da Embaixada daquele país, de um programa de estudos sobre administração pública e sistema político. Após seu retorno ao Brasil, assume, em
} 
1997, a Diretoria de Desenvolvimento Regional e Social do Banco Nacional de Desenvolvimento Econômico e Social (BNDES). Em 1998, com 41 anos de idade, Hartung lança-se como candidato ao Senado Federal, sendo eleito com a maior votação até então registrada no Espírito Santo (780 mil votos). Filia-se, em 1999, ao PPS, e, em 2001, ao PSB. Em 2002, candidata-se a governador do Espírito Santo, sendo eleito no primeiro turno com $54 \%$ dos votos válidos. Reelege-se a governador do estado, em 2006, no primeiro turno, com 77,27\% dos votos válidos. Em 2014, Hartung volta a concorrer ao cargo de chefe do executivo, sendo novamente eleito no segundo turno com 53,44\% dos votos válidos, vencendo seu concorrente Renato Casagrande.

${ }^{2}$ No momento em que este artigo está sendo escrito, as localidades nas quais já foram instaladas unidades da Escola Viva são os seguintes: Afonso Claudio, Cachoeiro de Itapemirim, Cariacica, Colatina, Ecoporanga, Guacuí, Iúna, Linhares, Montanha, Muniz Freire, Pedro Canário, Planalto Serrano, São Mateus, São Pedro e Vila Velha.

Referências Bibliográficas

ANDERSON, Perry. Balanço do neoliberalismo. In: SADER, E.; GENTILI, P. (Orgs). Pós neoliberalismo: as políticas sociais e o Estado democrático. Rio de Janeiro: Paz \& Terra, 1995. p. 9-23.

BESSA, Laureen. Plano de educação é aprovado após bate-boca na assembleia. ES Hoje, Vitória, 17 jun. 2015. Política Capixaba. Disponível em: <http://www.eshoje.jor.br/_conteudo/2015/06/politica/politica_capixaba/30810-plano-deeducacao-e-aprovado-apos-bate-boca-na-assembleia.html>. Acesso em: 28 jul. 2016.

BÉDARIDA, François. Tempo presente e presença da história. In. FERREIRA, M. M.; AMADO, J. (Org.). Usos e abusos da história oral. Rio de Janeiro: FGV, 2005. p. 219229.

ESPIRITO SANTO. Discurso de posse do governador Paulo Hartung no palácio anchieta, em $1^{\circ}$ de janeiro de 2007. Portal do Governo do Espírito Santo. Vitória, 01 jan. 2007. Disponível

em: <http://www.es.gov.br/banco\%20de\%20documentos/discursos/Discurso_de\%20Posse20 07_PalacioAnchieta.pdf $>$ Acesso em: 28 set. 2016

FACHETTI, Eduardo. A primeira promessa de PH começa a sair do papel. Gazeta On Line, Vitória, 6 mar. 2015.2 Disponível em: <http://www.gazetaonline.com.br/_conteudo/2015/03/opiniao/colunas/praca_oito/389085 8-a-primeira-promessa-de-ph-comeca-a-sair-do-papel.html>. Acesso em: 06 jul. 2016.

GOUVÊA, Gustavo. Escola viva: professores, alunos e pais falam sobre projeto do governo do ES. ES Hoje, Vitória, 17 abr. 2015. . Disponível em: <http://www.eshoje.jor.br/_conteudo/2015/04/noticias/educacao/28848-escola-vivaprofessores-alunos-e-pais-falam-sobre-projeto-do-governo-do-es.html>. Acesso em: 30 mai. 2016.

GONÇALVES, A. dos S.; SILVA, M.; PALASSI, M. P. Associativismo e representação institucional: o movimento empresarial Espírito Santo em ação. In: XIV CONGRESSO BRASILEIRO DE SOCIOLOGIA, 2009, Rio de Janeiro. Anais eletrônicos.... Disponível em:

http://www.sbsociologia.com.br/portal/index.php?option=com_docman\&task=cat_view\& gid=226\&Itemid=170>. Acesso em: 02 set. 2016.

HARTUNG, Paulo. O governador do Espírito Santo, eleito num momento que o estado é considerado um dos mais violentos do país, explica a busca de ajuda do governo federal para restaurar a segurança. Roda Viva, TV Cultura, São Paulo, 28 de abr. 2003. Entrevista concedida pelo Governador do ES. Disponível em: 
<http://www.rodaviva.fapesp.br/materia/504/entrevistados/paulo_hartung_2003.html>. Acesso em: 19 abr. 2016.

MAJESKI, Sérgio. Plano estadual de educação. Entrevista concedida ao programa Bom dia Espírito Santo, Vitória, 9 jun. 2015. Disponível em: <https://www.youtube.com/watch?v=Cdc7D2rKpNM>. Acesso em: 05 mai. 2016.

NASCIMENTO, Rafael Cerqueira. A narrativa histórica da superação do atraso: um desafio historiográfico do Espírito Santo. 2016. 291f. Tese (Doutorado em História) - Programa de Pós-Graduação em História, Universidade Federal do Espírito Santo, Vitória, 2016.

OLIVEIRA, Dalila Andrade. A política educacional brasileira: entre a eficiência e a inclusão democrática. Educação e Filosofia Uberlândia, v. 28, n. especial, p. 225-243, 2014.

OLIVEIRA JÚNIOR, Rui Barboza. As políticas educacionais do segundo mandato do governo Paulo Hartung e seus impactos no trabalho docente. 2013. 148 f. Dissertação (Mestrado em Educação) - Programa de Pós-Graduação em Educação, Universidade Federal do Espírito Santo, Vitória, 2013.

OLIVEIRA, Renata. (2015a). Assembleia aprova escola viva sob protestos dos estudantes. Século Diário, Vitória, 10 jun. 2015. Disponível em: <http://seculodiario.com.br/23258/8/escola-viva-e-aprovada-na-assembleia-e-estudantesfazem-protesto>. Acesso em: 13 jun. 2016.

. Casagrande e Hartung se atacam indiretamente usando outros candidatos. Século Diário, Vitória, 29 ago. 2014. Disponível em: <http://seculodiario.com.br/18530/8/casagrande-e-hartung-se-atacam-indiretamenteusando-outros-candidatos-1>. Acesso em: 27 jul. 2016.

(2015b). Educação seletiva. Século Diário, Vitória, 28 nov. 2015. Disponível em: <http://seculodiario.com.br/26099/14/educacao-seletiva> Acesso em: 07 abr. 2016.

(2015c). Em protesto ao Escola Viva, estudantes ocupam Superintendência da Educação em São Mateus. Século Diário, Vitória, 7 dez. 2015. Disponível em: $<$ http://seculodiario.com.br/26252/8/estudantes-de-sao-mateus-ocupam-superintendenciacontra-escola-viva> Acesso em: 27 mai. 2016.

(2015d. Justiça proibe escola viva no Conde de Linhares. Século Diário, Vitória, 21 dez. 2015. Disponível em: < http://seculodiario.com.br/26490/8/justica-proibe-escolaviva-no-conde-de-linhares-em-colatina>. Acesso em: 17 ago. 2016.

(2015e. Mobilização de estudantes contra 'reorganização' da educação começa a ganhar força no Estado. Século Diário, Vitória, 7 dez. 2015. Disponível em: <http://seculodiario.com.br/26236/8/ijreorganizacaoij-manifestacoes-de-estudantespipocam-no-estado>. Acesso em: 25 mai. 2016.

(2015f). 'Todo o programa deve ser alterado e reconstruído para ser eficiente'. Século Diário, Vitória, 02 mai. 2015. Disponível em: < http://seculodiario.com.br/22573/8/ijtodo-o-programa-deve-ser-alterado-e-reconstruidopara-ser-eficiente>. Acesso em: 26 mai. 2016.

PAULO hartung, do PMDB, é eleito governador do ES. G1, Vitória, 05 out. 2014. Eleições 2014, Espírito Santo. Disponível em: <http://g1.globo.com/espiritosanto/eleicoes/2014/noticia/2014/10/paulo-hartung-do-pmdb-e-eleito-governador-doespirito-santo.html>. Acesso em: 14 abr. 2016.

PAULO Hartung toma posse como governador do Espírito Santo. Gazeta On Line, Vitória, 1 jan. 2015. Disponível em: < http://www.gazetaonline.com.br/_conteudo/2015/01/noticias/politica/3885511-paulohartung-toma-posse-como-governador-do-espirito-santo.html>. Acesso em:14 abr. 2016.

PESSINE, Karina Melo. Organização parlamentar, processo decisório e produção legislativa no cenário capixaba: uma análise da assembleia legislativa do estado do Espírito Santo na 
$16^{\text {a }}$ legislatura (2007-2010). 2013. Dissertação (Mestrado em Ciências Sociais) Programa de Pós-Graduação em Ciências Sociais, Universidade Federal do Espírito Santo, Vitória, 2013.

RABELO. Governo Hartung trata a educação pública como mercadoria. Acrópole Blog. Vitória, 20 jul. 2010. Disponível em: <http://jbaltamirano.blogspot.com.br/2010/07/governo-hartung-trata-educacao-publica.html> Acesso em: 27 mai. 2016.

SOUZA, Dayana. "Atual governo tropeçou nas próprias pernas", critica o candidato Paulo Hartung. ES Hoje, Vitória, 29 jun. 2014. Disponível em: <http://eshoje.sites.fiveedit.com.br/index.php?id=/noticias/materia.php\&cd_matia=amp;1 9403\&dinamico=1\&preview=1\&materia_imprimir=1>. Acesso em: 02 mai. 2016.

TRENTO, Tânia. Sindiupes faz campanha por escola integral democrática, plural e inclusiva. SINDIUPES, Vitória, 26 abr. 2015. Disponível em: $<$ http://sindiupes.org.br/blog/sindiupes-faz-campanha-por-escola-integral-democraticaplural-e-inclusiva/>. Acesso em: 07 jul. 2016.

VICTOR, Duilo. Paulo Hartung diz que não vai devolver "pedradas" que leva durante campanha. Gazeta On Line, Vitória, 10 ago. 2014. Disponível em: <http://www.gazetaonline.com.br/_conteudo/2014/08/especiais/eleicoes_2014/1494476paulo-hartung-diz-que-nao-vai-devolver-pedradas-que-leva-durante-a-campanha.html> . Acesso em: 30 jun. 2016.

VALFRE, Vinicius. Carro-chefe de Hartung é alvo de críticas. Gazeta On Line, Vitória, 17 mar. 2015.

Disponível em:

http://www.gazetaonline.com.br/_conteudo/2015/03/noticias/politica/3891843-carrochefe-de-hartung-e-alvo-de-criticas.html>. Acesso em: 29 jun. 2016. 